\title{
The Politics of Data:Uncovering Whiteness in Conventional Social Policy and Social Work Research
}

\author{
Ann Curry-Stevens ${ }^{1}$, Amanda Cross-Hemmer ${ }^{2}$, Nichole Maher ${ }^{3}$, Julia Meier ${ }^{4}$ \\ ${ }^{1}$ School of Social Work, Portland State University, Portland, USA; \\ ${ }^{2}$ Center for Improvement of Services to Children \& Families, Portland State University, Portland, USA; \\ ${ }^{3}$ Native American Youth and Family Center, Portland, USA: \\ ${ }^{4}$ Coalition of Communities of Color, Portland, USA. \\ Email: currya@pdx.edu \\ Received April 29 ${ }^{\text {th }}, 2011$; revised June 21 2 st 2011; accepted August $2^{\text {nd }}, 2011$.
}

\begin{abstract}
The implementation of a robust community based participatory research (CBPR) study in Multnomah County, Oregon, has detailed broad and deep racial disparities across 27 institutions and systems. The process of this research has led to the identification of numerous practices that misrepresent and negate the experiences and very identity of communities of color. The research draws from engagement with numerous databases from the Census Bureau, the Bureau of Labor Statistics, the Substance Abuse and Mental Health Services Administration, and various administrative databases. The core issues at hand are population undercounts, understudy of the unique characteristics of these communities, inaccuracies in how data are codified and analyzed, and data collection efforts that are infused with white centrism and a colorblindness that renders issues minimized and the experiences of communities of color obscured. Collectively, we analyze this experience to suggest that much conventional policy research while wrapped in a cloak of objectivity is in fact a reproduction of whiteness that renders communities of color invisible, marginalized and misunderstood. The impact of these practices is to extend whiteness into the arena of policy research, and correspondingly extend dynamics of oppression and white centrism. The paper profiles each area of the policy research process that reflects and reinscribes whiteness and concludes with an articulation the reach of such conventional practice and outlines an avenue to reduce the influence of whiteness.
\end{abstract}

Keywords: Communities of Color, Measurement, Policy Advocacy, Policy Research, Racial Disparities, Whiteness.

\section{Introduction}

Whiteness is recognized to pervade many areas of social work practice (Baines, 2007; Dominelli, 2002, Hick, Fook, \& Pozzuto, 2005). While we understand that research endeavors are typically ripe with dynamics of oppression and privilege (Lawrence-Lightfoot, 1993; Brown \& Strega, 2005), there are few insights to date that profile how social work research in the policy arena is similarly ripe with power issues and, as we will show, embedded in the research tools themselves. Beginning in the UK, the efforts of Wilson (2001) illuminate the deficiencies of a stance of neutrality in database construction. Her work uncovers the biases within how those who engage in large survey construction are prone to reproducing dominant discourses concerning the elderly. Wilson's work challenges the field to build routine practices to unveil biases in how experience is theorized, database tools constructed and then analyzed. In the context of race and racial identity, the efforts of Zuberi \& Bonilla-Silva (2008) provide an array of evocative considerations for how to discern research conventions that reproduce whiteness.

Defining whiteness as the process of valuing white identities over those of color gives us insight into the mechanics through which white privilege is reproduced. Whiteness, in our application, is both the process and the outcomes of systems, institutions, practices, behaviors, and discourses that differentially act on whites and people of color. Such are acts of privilege and simultaneously those of oppression, even when not intended. The intention of policy makers (and in this case, database de- velopers, administrators, and researchers) is inconsequential to assessing the whiteness framework for these policy practices; instead it is the impact that is of significance.

Repeated encounters with policy practitioners and researchers typically reveal that these white-dominated professionals have not considered the implications of their practices. A lack of awareness is the predominant dynamic. Secondly, in the research team, we have become aware of the complexity of these issues due to the urgings of our partners with the Coalition of Communities of Color. Our catalysts are thus people of color. The mainstream policy and research communities typically do not have such nor accountabilities to bring such issues to the foreground of their attention. The dynamic here is thus one of neglect. Another factor is that advocates within communities of color are typically underfunded and overworked. The members of the Coalition know many of these issues experientially, but have little time to advocate for changing policy research practices as they are busy dealing with more concrete needs of their communities. Finally, we assess that these issues are sometimes borne of intention. In several instances, the data surrounding disparities and inequities have been hidden by the institutions that advance such practices.

While analysis of whiteness does not depend on the intention with which research practices were conducted, but rather their outcome, we have, however, found instances where there is intention to obscure the experiences of our communities. The most profound of these experiences is the Census Bureau's own upward revision of its 2000 numbers (US Census Bureau, 2004). Two major studies followed this release, both of which 
were not adopted by Congress. It takes an act of Congress to accept Census figures and the best interpretation of the political environment is that the domination of Republicans ensured that these issues did not come to a vote. Two vested interests were, and continue to be in play. The first is that significant funds are tied to Census numbers and heightened numbers result in larger federal expenditures. A study by National Economic Consulting (2001) documents that undercounting in the Census was approximately 3.3 million (or $1.18 \%$ ) and it set the net financial value of these undercounts at $\$ 478$ million over 10 years.

Additionally, Census figures have far-reaching consequences in federal policy. Population counts are used to determine the number of appointments in the House, for drawing Congressional districts within states and local governments and school district boundaries. These issues are directly tied to political voice and the access that local communities have for political representation.

The direction of the undercounting bias has a significant regional impact. Undercounting occurs when people move frequently, when they refuse to answer the forms, when they do not have phones and when they do not have good enough fluency in official languages to answer forms. These problems exist most frequently within poor inner cities, and are more likely to undercount children (National Economic Consulting, 2001). The composite impact of all these factors is likely experienced most dramatically among communities of color. The impact of fixing these figures is to grant greater political representation to these communities - and the implicit bias becomes an explicit one-one of political choice to ignore the Census Bureau's upward revisions.

Most US policy practitioners rely on official data sets such as the Census and the American Community Survey to document important dimensions of the experiences of communities of color. These are generated by conventional practices within mainstream society, and as we will illustrate, that are imbued with notions of colorblindness and innocuous understandings of the influence of white privilege. Policy researchers use these databases to document how social conditions challenge communities of color. But these practices have failed to detail, and perhaps even notice, the ways in which the typical datasets of policy research are replete with whiteness. Bringing a critical lens to the foreground builds insights into research practices that continue to marginalize and render invisible communities of color.

Over the last two years, a team of researchers and community practitioners have been involved in a community-based participatory research project (CBPR) in Multnomah County, Oregon with the goal of documenting the disparities facing communities of color in the region. The partnership is between researchers at the School of Social Work at Portland State University and the Coalition of Communities of Color. A total of 28 different institutions and systems have been reviewed with significant results uncovered to document inequities that run broad and deep across all dimensions of life experiences (Curry-Stevens, Cross-Hemmer, \& Coalition of Communities of Color, 2010). The findings reveal substantial and worsening disparities, with distinctly toxic conditions facing local communities of color. Disproportionality reaches from economic and education institutions, to social service institutions such as child welfare and justice, to programs that have intended to ameliorate disparities such as protected government contracting initiatives. Quite uniformly, all show marked disparities and typically are worse than the national averages for such disparities, and worse as well than King County to the north of us, where Seattle is based. Despite the progressive identity of the region, communities of color are experiencing previously untold inequities and in the vast majority of the measures, the situation is worsening. Since the report was released in May 2010, the Coalition has been engaged in advocacy efforts to change the policy environment that beleaguers communities of color. While the goal of the research has been to document the disparities, a corollary of this research has been to uncover shortcomings of available data, and make recommendations for revised practices. These discoveries form the basis for this paper.

This paper will contextualize the discoveries within dominant discourse and white privilege, explain why this work matters, and then illustrate several decision points within the policy research process. We primarily center our comments on the array of population surveys on which the field relies, but also stretch into some standard research practices at the stages of analysis and dissemination. Our work is organized into the following steps: data form design (and how race and ethnicity questions are asked), data collection method, coding of data, representation and dissemination of data, and issues related to dominant discourses about race and ethnicity. The affects of the discovered whiteness are laid out and solutions suggested.

\section{Dominant Discourse and White Privilege}

All features of this research experience are best explained by a critical framework that centers issues of power and inequities. These research practices are infused with white centrism and a colorblindness that renders issues facing communities of color minimized and populations themselves close to invisible. In the funding arena, there is a kiss of death for having a small "n." Our work illustrates that both the small " $n$ " and all other visibility issues are exacerbated by conventional policy research practices.

Complicating this dynamic is that many within communities of color are reticent to self-identify as a person of color. Histories of genocide, persecution and cultural obliteration create fear of the state. Even if this experience is in another country, such attitudes flow into relationships with the state in the USA. In addition, the USA has not been exemplary in wielding its power with communities of color. Internment of Japanese Americans, genocide of Native Americans, seizure of Native American children and their placement in residential schools, and the enslavement of African Americans are all state-legislated policies which creates fear and distrust that extends to tools of the state such as official surveys.

This history, coupled with self-deprecation of one's minority racial identity, is likely to create an impetus for individuals to deny their identification as a person of color. Younger people of color are less likely to deny their racial identity as social movements have sought to increase their pride of identity and resistance practices include affirming one's minority status. The impact of these shifts in discourse are illustrated in the local pattern of the size of the Native American community. The growth of the community counts in Multnomah County in Census 1990 to 2000 of 6967 people (a jump of 118\%) cannot be explained by migration and birth rates. Instead, the community perceives that the spike in identificating as Native American is due to heightened willingness to identify as Native American.

\section{Why This Work Matters}

Before sharing our findings, we must briefly profile the im- 
portance of accuracy in documenting our communities of color. Why does this matter so much? While it might appear to be "simply" an issue of what Fraser (2003) calls the "politics of recognition," the depths of this issue stretch extensively into the lives and fabric of society among communities of color. The consequences are many: since "dollars follow numbers," communities of color have lesser claim to society's collective resources (primarily government budgets) when they have smaller numbers. Current estimates are that $\$ 1439$ /year is foregone for each person not counted by the Census Bureau (Reamer \& Carpenter, 2010). Without such numbers, little claim exists. Additionally, numbers serve to leverage influence. Consider the policy-making table: when groups have sizeable numbers, their representatives are often invited to consultations and sometimes to participate in making decisions. When they do not, they are rarely invited to join. While the conditions of joining are often tokenistic, at least policy makers realize they do not have enough legitimacy to make decisions for underrepresented groups. An easy synthesis of these issues is that larger numbers equals power, frequently translatable into dollars.

\section{Survey Design Issues and How Race and Ethnicity Questions Are Asked}

Let us begin by first asking why questions of race and ethnicity are asked. At its most basic level, such questions are asked so as to enable the policy making community to assess racial progress and the impacts of affirmative action policies (Humes \& Hogan, 2009; Young, 2000). The categories constructed to ask such questions give us the dimensions of the disaggregation possible within the dataset. Probing more deeply, the questions of race and ethnicity seek to let researchers assess moral and political dimensions of the experiences of people of color, specifically aiming to assess whether the policy environment and related laws are successful in "redress of past injustice and/or bring about future equality” (Alcoff, 2000: p. 171). Classifications are thus intended to accurately capture more than simply some typology of identity and difference instead their purpose is to "establish useful distinctions that might elucidate our political realities and moral responsibilities" (Alcoff, 2000: p.171).

The social construction of race is dynamic, changing across time. While race and racial identifiers hold the possibility for studying the current state of racism in the USA, they are problematic for many reasons. The first is that dimensions of racism are not experienced similarly across a racial group, such as "African American." Here, those clearly from a lineage of slavery are combined with others who have escaped such damage, although Alcoff (2007) surfaces the possibility that a heritage of diaspora serves to render all Africans similarly harmed by racism. Secondly, the term masks additional features that serve to buffer or exacerbate experiences of racism. The racial identifier "black" combines all Africans regardless of the lengths of time they have been in the country such as those here for generations, eclipsing the forms of immigration under which one arrived in the country (which might range from refugees to business class immigrants carrying tremendous wealth into the country). We also combine those with varying degrees of "blackness" which serves to influence the extent of anti-black racism experienced. Corlett (2007) illustrates how the category "black" fails to identify the group of persons who deserve reparations from US slavery and thus constricts options for tracking the impacts of policies such as affirmative action.

The salience of racial identities thus has an ethnic, geo- graphic and temporal context. Racial identifiers are dynamic constructs, and each has its distinct strengths and weaknesses. Let us now share our reflections on the tensions created with the Census identifiers for our communities of color, of particular salience since the majority of databases we examined used the conventions in the Census and its surveys. To facilitate this discussion, we reproduce the two race and ethnicity questions contained within Census 2000 and used again in 2010. The vast majority of databases we examined used these same questions in their own administrative databases.

To begin, Latino identity is separated from racial identity. If one follows the directions by the Census Bureau in their training initiatives with canvassers, they advise Latinos to identify themselves as a distinct ethnicity, and then suggest to respondents the choice of defining themselves in the racial categories of "white" or "some other race," with a preference to encourage them to select "some other race." Our first concern is that the very construction of this tool requires Latinos to be "othered" and subsequently both implicitly and explicitly suggesting they are outsiders to the USA. Sue (2010) articulates that exclusionary practices such as this occur on a daily basis among communities of color with devastating impacts on health, well being and economic progress. The alternative is to identify oneself as "white" which is an inaccurate naming and results in a distortion of both white and Latino experiences. The persistent dynamic of "othering" racial minorities is one of implicitly claiming the superiority of those who are named accurately. This method of identifying Latinos is an act of marginalization and its corollary of imperialism is advanced (drawing from Young's 1990 framework of the five faces of oppression). When data practices require a community of color to identify themselves as "some other race," the very act of completing the survey reinforces one's social exclusion from US society, and simultaneously inscribes the inclusion of Whites, revealing the normative impact of such a construction of identity.

The history of the decision to exclude Latinos as a separate race is a political decision, with an expansive set of resources available to track the impacts and wisdom of this decision (including Gracia \& Greiff, 2000; Gracia, 2007). A synopsis of this challenge is that the decision to exclude Latinos as having a distinct race is a reflection of the success of many Latinos in their enfranchisement struggles and their social, political and economic gains in the USA, primarily in the nation's northeast region. This is far, however, from a universal achievement as Latinos in the south, west and northwest remain deeply marginalized and socially excluded from mainstream society. At the national level, $47 \%$ of Latinos identify their race as white, while $53 \%$ of the same community do not, with the breakdown of this "some other race" category being that $42 \%$ identify their race as Latino (the remainder is a combination of more complex identities with the majority being black and the second largest being Native American) (Alcoff, 2000; Lafoya, 2004). In total, $97 \%$ of the "some other race" category is Latino.

When research is conducted at the microfile data level, and disaggregated by ancestry, a class and nationality divide emerges. Tafoya (2004) illustrates that $85 \%$ of Cubans identify as white, while only $16 \%$ of those from the Dominican Republic identify as white. Mexicans, who are the largest of the Latino communities, have a divided identity with $47 \%$ identifying as white. In our region, Latinos prefer to be identified as people of color, as there is little evidence that they have benefited from whiteness and have been largely subjugated to colonization. Indeed, most Latinos share this legacy, but are personally tied to this history in varying ways. Tafoya (2004) illuminates features of these differences among the Latino community. Latinos 
who identify as white are the wealthiest, best educated, best employed of the Latino community, and live in closest proximity to white communities.

While we recognize that the Latino identification issue remains contentious, we report that our local Latino community wishes to be seen as a distinct race and to be defined as a community of color. We also highlight that the convention of naming Latino identity as an ethnicity as opposed to a race is deeply problematic since it obscures the challenges facing the Latino community, as well as hiding the advantages experienced by the white community. Essentially, Latino people “disappear” in the racial identifiers and this construction of identity serves to minimize our ability to understand the racial inequities the community faces. Our interpretation of this dynamic is that the process of separating Latinos from other communities of color is a convoluted and misguided attempt to affirm the marginal gains that have been experienced by limited portions of the Latino community. The net impact is to erode our ability to examine the racial inequities experienced by the community (for creating this community as ethnic creates abysmal research challenges to allow for accurate analysis of community experiences) and it extends and perhaps entrenches a divide in the solidarity needed among communities of color to resist discrimination and racial inequities.

The racial identifying question for Native Americans is problematic as it appears from the flow of this question that one needs to be tribally enrolled to answer this question, which is not intended. This signals to the community to not list in this section as a separate race if one is not enrolled. We also believe that the historic relations of colonization and particularly of tribal termination narrows the community's likelihood of selecting this identifier. Concerns exist among our Native American community that this process simultaneously engages in two troubling practices: the first being that it ties Native identity to enrollment, which for many is a source of deep pain. Tribal enrollment can be very difficult, particularly for the thousands of Native Americans who have been apprehended by the state either through the residential boarding schools or through the child welfare system who have had ties with their communities involuntarily severed. The second impact is that by asking Native Americans to identify only one tribe in this section, the state is requiring that Natives afford one tribe primacy over others with which we may also be affiliated. Such is not Native culture and this does harm to our communities through the very construction of racial identifiers in the Census and other data collection forms that draw from Census conventions.

Among the African American community, no supplemental identifiers are permitted for African Americans, obscuring their ancestry and origin as included in the Asian details. In our region, the needs of different African American groups diverge, with those of recent African ancestry seeking identification as a group with specific needs. Among Native Americans, reducing one's identity to just one tribe causes an excessive curtailing of culture. In addition, the terminology for African American that includes "Negro" is offensive to many. While it is understood that there is an age variance here, with older African Americans preferring the term "Negro," many African Americans deem it offensive as it is cconsidered a racial slur by leaders of the civil rights movement, and the term has since been abandoned for its association with slavery and segregation (Kiviat, 2010). One African American woman told us she found it to be "code for the other $\mathrm{N}$-word that identifies us." Offending respondents is one way to make community members not complete the survey, and, by impact, an act of racism.
For the Asian/Pacific Islander community, greater complexity of racial identifiers exists. There remains, however, a pattern of "othering" those communities not listed in the list.

Turning now to other systems for identifying race and ethnicity, we find that while the Census Bureau has stayed away from the "multiracial" category of identity as an avenue to handle identities when one holds more than one race, some other databases have not (the Substance Abuse and Mental Health Services Administration (SAMSHA) and Oregon's Kindergarten Teacher Survey are examples). These surveys do not permit multiple identifiers to be used, presumably trying to circumvent the later challenge of how to code and represent such persons. As researchers and communities members seeking to heighten the visibility of communities of color, and support self-determination, this practice rolls back our progress. While seemingly an advance (for there have been many community members who want to affirm their multiracial identities), the impact is to obliterate the specificity of these data. For example, SAMHSA's National Survey on Drug Use and Health, 2009, uses a " 2 or more races" category that is $8 \%$ of the total number of respondents in the survey. We examined the findings of this survey to ascertain the dynamics of alcohol use within the Native American community. The data show that whites now surpass Native Americans in their binge use of alcohol at rates that are $11.7 \%$ higher (24.8\% compared with $22.2 \%$ ). But an additional $24.1 \%$ of respondents indicating high alcohol use are "multiracial." If we add this Figure 1, or even a fraction of it, to the Native American category, Native Americans quickly surpass whites in their binge alcohol use. How to disaggregate these data is not information provided with the survey report. To determine how many of this $24.1 \%$ belong in the Native measure, we would reference the USA ACS data for those Native Americans who identify themselves as having more than one race. This calculation results in $32.8 \%$ of the total multiracial identity belonging to Native Americans. Applying this figure to our $24.1 \%$ rate, we should recalculate the alcohol use

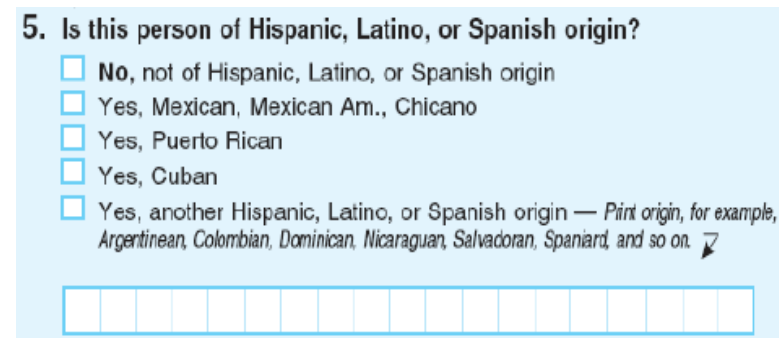

6. What is this person's race? Mark $\bar{x}$ one or more boxes.

$\square$ White

Black, African Am., or Negro

American Indian or Alaska Native - Print name of enroled or principal tibe. $\vec{\nabla}$

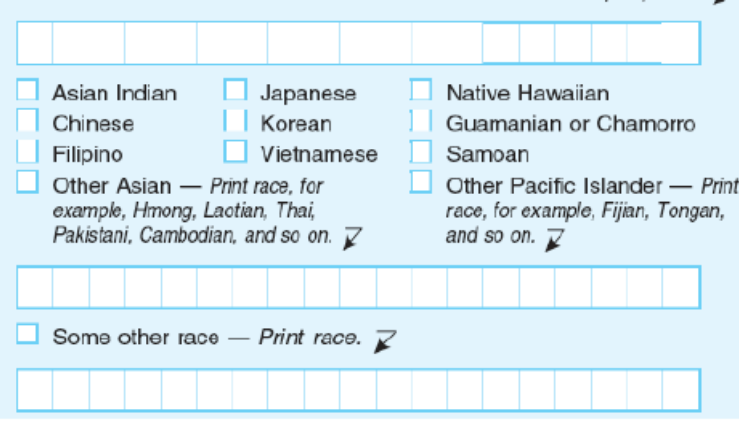

Figure 1.

Census Bureau's ethnicity and racial identifiers. 
rate for Native Americans to be: $32.8 \%$ of $24.1 \%$ ( $=7.9 \%$ ) additional, which equals $30.1 \%$ binge drinking levels.

Thus Native American binge drinking levels continue to be higher than that of Native Americans, though if one were to consider only the reported data for each of Native and Whites, a misleading interpretation would result.

In another example, the Oregon Department of Education in 2006 changed the racial categories for its survey of Kindergarten teachers on the developmental benchmarks of incoming students and the type of early education experiences they had had. This category served to mask disparities that existed in the differential experiences of children of color, when compared with the developmental achievements of white children. In its 2008 version of this survey, the Oregon Department of Education eliminated its use of this racial category.

What quickly becomes clear is that multiracial identifiers obscure and render invisible the experiences of specific communities of color through an array of practices which inaccurately ask people of color to define their own race and ethnicity. These data are then used to identify disparities and inequities, and inaccurate data (particularly undercounting, but also the complex problem created by holding Latino identity as an ethnicity) serves to reduce the visibility of disparities among communities of color. The construction of racial identifiers in the Census serves as well to "other" our communities in harmful ways, and typically inscribes identity in ways that sustain marginalization and powerlessness, while simultaneously contributing to the elevation of white US society. While the marginalization process is harmful, the differential impact on white communities and communities of color makes the impact worse, for deprivation is the consequence of these practices, and polarization of deprivation (with excess accruing to the white community) deepens the harms experienced.

\section{Data Collection Methods}

Turning now to data collection methods, we highlight the issue of who completes the race and ethnicity identifiers for community members. The core concern is that when others complete these identifiers for people of color, there will typically be errors that stem from one's appearance. While we have heard stories of Census canvassers doing this on behalf of respondents, this is not official practice. In all cases, they are to ask. But comfort with the questions and a lack of appreciation for the significance of the issue results in uneven practices. For Census 2010, communities of color in Multnomah County made official requests to train canvassers on this issue. This request was denied as it is official practice to not allow such training, despite the support of our local Complete Count committee.

Two additional examples are provided. The first is in the health arena where death rates serve as the basic measure of the impact of mortality on a population. When measuring racial disparities, mortality data from death certificates supply the numerator for death rates, while census population estimates provide the denominator. The primary source of mortality data in the United States are death certificates. On death certificates, race reporting is typically the responsibility of a funeral director. Funeral directors often must rely on personal observation to make this determination, or alternately, must gather this information from whoever accompanies the body at the time of death. Understandably, such questions are avoided wherever possible, with appearance thus being estimated. This means that people of color may be identified as belonging to another group on their death certificate.

Race and ethnicity specific death rates are used to calculate all-cause and cause-specific mortality differences between the racial and ethnic subgroups in the United States.

Studies have found that self-report (on Census or other survey) and death certificate proxy report of race and ethnicity matching varies significantly by racial or ethnic grouping, and that this disparity has persisted over time. The most recent research on this confirmed that the error rate in this reporting is as high as $42 \%$ among Native Americans, and to a lesser but still significant group among the Asian/Pacific Islander community, at approximately $12 \%$ (Centers for Disease Control and Prevention, 2008). This confirmed earlier studies revealing the same pattern with data dating as far back as 1979 (Frost \& Shy, 1980; Stehr-Green, Bettles, \& Robertson, 2002). This inaccuracy pervades all ages of deceased people from infants in hospitals to elderly in their own homes.

The impact of these errors is to define large numbers of deaths as white when in fact they are people of color, an error that serves to underestimate the mortality rates among communities of color. Correction for death certificate misclassification can make a large difference to both age-specific and age-adjusted death rates: for the Native American population, correcting for misclassification makes the age-adjusted death rate climb from $85 \%$ to $111 \%$ of that of the white population. This changed a relative large Native American-to-white mortality advantage to a relatively large disadvantage.

Death rate mortality data is used to highlight health disparities and drives initiatives aimed at improving the public's health. Incongruence between race and ethnicity classification on numerators and denominators of death rates has the potential to bias race- and ethnicity-specific mortality differentials, which in turn impacts policy and funding allocations. The case above is striking-imagine the funding and policy consequences flowing from an assumption of a mortality advantage where in reality a negative disparity exists.

For example, imagine the impact that $42 \%$ misclassification on death certificates might have on the resources flowing to the Native American community. To provide health care for this increasingly urban area, the Indian Health Service (IHS) awards contracts and grants to 34 nonprofit agencies located in major metropolitan areas across the United States. As a group, Urban Indian Health Organizations have minimal technological infrastructure with no shared standardized data system that can be used to provide a collective description of the target populations they serve (Castor et al., 2006). This raises the stakes and need for other data sources to provide accurate, reliable epidemiological information about the population. Such information is necessary for these organizations to allocate their resources effectively, customize health care services, implement program evaluations, and launch policy initiatives. High rates of racial misclassification in mainstream health-related data make it harder for these organizations to advocate for increased funding or to improve organizational efficiency.

Our second example of the errors involved when others define the race and ethnicity of people of color comes from state child welfare administrative data. Filled out by child welfare workers, and vulnerable to their discomfort in even asking the question, there is a huge "unknown" racial identity among children in foster care in Oregon. Children with racial/ethnic designations of race "unknown" represented $12.8 \%$ of the foster care population. Of children still in care during this study's 6 month analysis period, $42.8 \%$ of these "race unknown" children 
had been in foster care 1 year or longer (Cahn, et al., 2009). This means that the state does not know the race of these children, even though they have had guardianship responsibilities over their lives for at least a year.

An additional difficulty exists within data collection methods. There are language limitations in data collection. While most contemporary forms are available in Spanish and Spanish-speaking translators and interviewers are typically available, there is a significant population that speaks neither English nor Spanish. In Multnomah County, 19\% of residents speak a language other than English at home. Of these, half speak English "less than very well." This pattern is similar for the nation-wide data. Only 6\% of residents (about one-third of the non-English homes) speak Spanish at home, leaving roughly $6.5 \%$ of individuals unable to communicate adequately in English or Spanish for the purposes of a survey. It is highly likely that the vast majority of this population are people of color, meaning that their experiences are routinely omitted for major data collection processes. While there is a measure called "linguistic isolation" that is substantially lower than these data, this measure depends on the presence of a youth over 13 years of age to interpret for older non-English speakers. Many survey topics salient to identifying disparities are not appropriately filtered through a youth in the family. The net impact of language limitations is that databases will have more accurate and larger samples of those in white and English-speaking communities-an example of whiteness, which is not intended but nevertheless is the impact.

\section{Coding of Data}

When data reports on the experiences of families and households (as opposed to individual level data), there is an embedded undercounting of communities of color. The identity of the "head of household" determines the identity for the entire family or household. When families hold a shared identity, this is not a problem. For mixed race families, however, mixed race identities of children disappear. If we assume that there are equivalent numbers of mixed race couples with white men as head of the household and men of color as head of the household, then there is a proportionate under counting going on. Notice, however, that their children will all be mixed race and all will be children of color. Thus the net effect of this bias will be to undercount the population of communities of color.

The second issue in data coding flows from the federal Department of Education which has mandated that all reporting to the federal government code all Latino persons who are also identified as other races solely as Latino (US Department of Education, 2007). This means that a student who is both Latino and Native American will be coded only as Latino. In this sense, the federal government has dictated that Latino identity is to "trump" all other racial identities. This dynamic is most significant for the Native American community that has the largest overlap with Latino communities. While we appreciate efforts to redress overcounting, and to have population counts clearly add up to $100 \%$, this policy will render other communities of color significantly less visible. Local practices of more details and equitable reporting are not prohibited, but cost constraints may compel local boards of education and state agencies to follow suit.

\section{Representation of Data}

This dimension of the research process addresses the com- munication of data in the public arena. There are four issues in this section: the aggregation of community experiences into "average" reports, the separation of Hispanic communities from other racial groups, the inappropriate aggregation that "hides" community specifics, and the suppression of data for various purposes.

One pronounced issue is the failure of research practices to routinely disaggregate important data by race. While it is possible to track patterns in this area, we instead share our experience as indicators of these failings: time after time, too little data was available on disparities as we aimed to collect these findings for our research reports. Examples include incomes, unemployment (a pervasive problem even at the state level), wealth and expenditure data, child welfare (not corrected locally until late 2009), student discipline levels (still not in the public arena), social assistance recipient numbers, health issues prevalence rates, and Head Start service numbers.

Our second issue flows from the data representation of Latinos as a non-racial group. Such grouping causes findings to be awkward to comprehend, and implies accuracies that do not in fact exist. In Cahn et al (2009), the disproportionality data from local child welfare practices highlights how reports become cumbersome and even impossible to work with. Readers may be familiar with this format that places racial figures that total $100 \%$ and then post Latino identities below that total, with a separate figure for their population. When these results are viewed in the report, it appears as though Latinos experience very low levels of foster care-and seem to have a "halo" effect in how they are treated in child welfare. If, instead, we redid the calculations of Hispanics as a part of the total racial grouping, these numbers in fact reveal that there is a proportionate level of Latino children in foster care. Recalculating these numbers has been possible as the research was also conducted in our university department, meaning we had access to the original counts - a feature rarely possible in research. An additional impact is that this separation of the Latino community highlights their separation from other communities of color, and by impact, narrows and even precludes the solidarity that exist between these groups.

In essence, the practice of separating out the Latino community serves to let researchers off the hook in ensuring that numbers accurately represent the size of communities of color. If conventional practices of showing Latino figures after total race data has been established were changed, the visibility of communities of color in service figures would be both more accurate but also more alarming. The net impact here is to diminish the visibility of Latino children in child welfare. The additional consequence is that we cannot conduct a consolidated evaluation of disproportionality for children of color as an entirety. This, in fact, is quite a tragedy as it precludes the possibility of solidarity among communities of color.

The third representation issue facing communities of color is the practice of inappropriately aggregating data for varied communities. While there are numerous examples, a contemporary practice in government contracting practices is particularly egregious. Most governments have policies to ensure that their contracts are awarded equitably to groups who face barriers in competing in open markets created by historic and current experiences of marginalization and discrimination. These groups are typically women, new small businesses and minority-owned businesses (our area of focus). In our region, Portland's metropolitan government aggregates all three to report on the success of this protected contracting program. The data is not available to let us see the effectiveness of this program in 
directing funds towars minority-owned businesses. This amalgamated reporting practice exists at all levels of government, with the exception of the City of Portland. Digging deeper, we find that only $4 \%$ of contracts under $\$ 100,000$ are awarded to minority-owned businesses, and $0 \%$ of contracts over $\$ 100,000$ are similarly awarded. Thus this practice of inappropriate aggregation serves to hide the inadequacy of the department and the policy to create an affirmative funding environment to help minority-owned businesses flourish. These failings have just been profiled in the media (Har, 2010) and are likely to catalyze some policy review.

The final dimension of faulty representation issues is the suppression of data that is deemed to have "insufficient" numbers to disclose. While this issue has already been shared as a catalytic moment for the research team at the start of this project, its implications are far-reaching. The Census Bureau requires 20,000 members in its American Community Survey (ACS) counts to report, but this same contraint does not exist for the findings of the Census itself, as it is not a representative sample, but rather a full count. The decision to drop the the long form, and increasingly rely on the ACS for population characteristics, when compiled with lack of sampling size growth, means that deterioration of available data is embedded in the Census Bureau's policies. This means that amalgamations of data will be increasingly featured instead of disaggregated data. This is of concern today and we accentuate that it will be of increasing concern in the years to come. We face this issue today in the Bureau of Labor Statistics' reporting on unemployment data. Insufficient numbers are avaiable to report on the race of unemployed Americans, and despite the "average" rate being available for the state of Oregon, nothing is available by race and ethnicity.

\section{Accessibility of Data}

Significant barriers exist to accessing racially-specific data. While the centralized databases of the Census Bureau are available free-of-charge, fees are incurred to access supplemental data. One example is the civil service hiring practices in the City of Portland. Fees are charged to make requests on the equity patterns of the workforce. In addition, special requests for Oregon's Department of Education data to provide more details on their equity practices (such as special education data disaggregated by race and ethnicity) take time and money. In addition, special runs of Census Bureau data is costly, as considerable expertise is needed to work with the microfile data. While costs and expertise can sometimes be addressed by academic researchers, community practitioners rarely have access to such capacities.

This biggest problem, however, is that each piece of data needs to be requested, often many times. Advocates need to agitate for access and this can use up valuable political capital that the community would prefer to retain for systems change work.

We want to impress upon all institutions that make data available to adopt research practices that makes transparent the experiences of communities of color. Routine disaggregation of data by race and ethnicity is essential. It is unfortunate that at the onset of the $21^{\text {st }}$ century in the USA that we still have to make the argument that not all Americans are the same, and that communities of color have life experiences that are profoundly unequal to whites. Aggregated data pretends this is not true and must be rejected.

\section{Effects of Whiteness in Databases}

The most basic element of undercounts is that each person missed in the Census population counts represents a loss of $\$ 1,439 /$ year to the region (Reamer \& Carpenter, 2010). Undercounting costs our community. In addition, these undercounted numbers are used not only to dictate federal and state levels of funding, but supplementally used by local governments and foundations to help them stratify funding allocation decisions for culturally-specific communities and services. Losing numbers is equated with losing financial resources.

Census figures are the gold standard for population counts. Despite the emergence of the ACS and the intention for it to increasingly inform community-level research, the population counts in the ACS are deemed "second best" as they are the results of a survey count as opposed to a complete census count. While we are beginning in mid-2011 to see the data from Census 2010, these data no longer include detailed experiences as the long form was dropped for 2010. For these details, we need to turn to ACS. The reach of Census is, however, expansive as these counts will be used to stratify and weight the figures of the ACS. Thus the impact of undercounting or miscoding communities of color is to largely pass on this error to the ACS. It also serves to stratify every other mainstream, administrative and institutional sampling method for the next ten years (until the next Census is administered).

Yet, the influence of Census and ACS figures stretch well beyond mainstream databases. Consider how researchers use these figures. For every piece of research that has a demographic component, such as a sample size, the method to stratify these samples is informed by the most recent Census figures or ACS. In addition, one assesses whether a community under study is representative of the wider population, is again, through Census and ACS. This means that when communities of color are undercounted or miscoded, this is reproduced throughout all such research. This means that insufficient numbers of people of color are included in research projects, and the official status of such projects is that they are "representative" and thus generalizable.

Additional problems with this reliance on the Census and ACS population counts is that they are used for two very important routine practices. In social work, service providers look at the profile of their service users and ascertain whether or not these numbers reflect the community where services are based. If these community figures do not match service user profiles, then barriers to accessing services are believed to exist. The second practice is that most employers who are either legislated to ensure their hiring practices are equitable. To ascertain whether the organization has employment barriers, the organization's workforce is compared with the local community population statistics. If people of color are undercounted throughout the country in Census and ACS, then the workforces across the nation are similarly too small, even though they may be deemed to be free of employment barriers. In essence, too small official figures mean that the bar for hiring is set too low.

Turning now to research that aims to understand disparities, the reference points for the "relative rate index" and the "disproportionality ratio" (or index) are, again, the ACS or Census figures. The very existence of disproportionality becomes fact based on an erroneous dataset. To remedy this situation, we want to alert researchers to the fact that the Census Bureau figures undercount communities of color, and reliance on the 
"alone" or even the "alone or in combination" figures will undercount their figures. The direction of this bias, is however, in the alternate direction. Undercounting the size of the Native American community in the denominator position (while the local data will be poised in the numerator position) will actually overdetermine the existance of disproportionality. Expanding this problem are difficulties with how the numerator is calculated, given that every survey uses either the Census race and ethnicity identifiers, or a method that is also problematice, such as having workers complete the form and are reluctant to ask the questions.

\section{Solutions}

Solutions to whiteness need to be advanced. The first is that the voice of communities of color need to be centered in these developments. It is this knowledge that needs to be held central to the development of alternatives. To some extent, this struggle is a post-modern challenge over meaning-making of communities' experiences, who gets to define them and how knowledge is created. This is ultimately "the validation of local knowledges" and an opening for "new systems of meaning making to affect social reality" (Wilson, 2005: p. 5). The benefits of such visibility may appear to be in advancing recognition, yet as described in this paper are in fact profoundly material and social, as social capital is tied to social capital which in turn frames possibility for inclusion and influence. Without sufficiently robust policy research practices that result in increased visibility, possibilities are foreclosed and the white dominant discourse continues unabated.

The work of the Coalition of Communities of Color has begun to articulate alternative practices. While such efforts are in early stages, we draw attention to the following principles for construction of improved data collection tools. First, people of color should be actively encouraged to identify their race and origin accurately and complexly. Second, racial designations should be amalgamated to be "race or origin" so as to be inclusive and to capture identity more fully and without practices of "othering" respondents. Third, Latinos should be included as an equivalent community among other communities of color. Fourth, individuals should be allowed to self-designate their identifies, having major groupings pre-named, with additional open spaces for supplemental identities. These categories should be developed in consultation with communities of color so as to reflect local conditions which are dynamic. Fifth, practice that allows multiple designations to be defined should continue. Sixth, the multi-racial category should be omitted as an identifier due to its potential to obscure the experiences of our communities of color. Instead of the multi-racial designation, two supplemental questions can be asked: do you identify as a person of color; and if you had to identify as only one race, what race would you like used? Seventh, wherever possible, data collection tools should be administered by those who share the same race as those completing the form, and in their local language wherever possible. Eighth, all contracts, subcontracts and grants should require compliance with, and reporting of, these same practices. Ninth, disaggregated data should be available to the community and readily accessible by the general public.

We believe that these principles will assist in opening conversations with policy researchers in numerous contexts. A final principle is to ensure that these dialogues occur with communities of color at the opening of the review and reform process, instead of latter stages when the scope of their possible involvement is curtailed.

\section{Conclusion}

The interactions of the policy research practices featured in this article serve a troubling pattern that render our communities of color undercounted, misinterpreted, and misrepresented. The extent to which our communities of color are visible, accurately counted and clearly portrayed has a significant impact on both recognition and redistribution.

The continued dynamic of centering the "average" experience as universal is an act of cultural imperialism as the white experience is presumed to speak for all. The interplay of invisibility and marginality, including the dynamic of promoting separation between Latinos and other communities of color, serve to preclude possibilities for solidarity and collective resistance to disparities and inequities among communities of color.

The function of whiteness as embedded in these database issues is to exacerbate the oppression of communities of color. While we have examined, so far, the technicalities in these policy research practices, the outcomes of these research practices are far-reaching.

Researchers and policy practitioners need to understand the shortcomings of their data and the decisions informed by them. Ensuring that communities of color are able to lay claim to collective resources and accurate representation is integral to modern-day enfranchisement struggles, particularly those that concern racial inequities and disparities. The influence of the conventional policy-related databases is broad and deep. Understanding the whiteness embedded in the ways in which race and ethnicity are asked, and the dominant discourse within which these policy tools are situated serve to reproduce whiteness. Such practices are accentuated when data from these sources are used for additional research practices, policy making and funding decisions.

\section{References}

Alcoff, L. (2000). Is latina/o identity a racial identity? In J. Gracia, \& P. DeGreiff (Eds.) Hispanics/latinos in the U.S.: Ethnicity, race and rights (pp. 23-44). New York: Routledge Press.

Baines, D. (2007). Doing anti-oppressive practice: Building transformative politicized social work. Halifax, NS: Fernwood.

Bell, J., \& Ridolfi, L. (2008). Adoration of the question: Reflections on the failure to reduce racial and ethnic disparities in the juvenile justice system. San Francisco, CA: W. Haywood Burns Institute.

Brown, L., \& Strega, S. (2005). Research as resistance. Toronto, ON: Canadian Scholars Press International.

Buery, R. (1998). GOP census politics. The Nation, 267, 6-7.

Cahn, K., Miller, K., Bender, R., Cross-Hemmer, A., Feyerherm, B., \& White, J. (2009). What we know about racial disproportionality and disparity in Oregon's child welfare system: Decision point analysis quantitative report. Portland, OR: Portland State University.

Centers for Disease Control and Prevention (2008). The validity of race and Hispanic origin reporting on death certificates in the United States. Vital and Health Statistics, 2, 1-32.

Curry-Stevens, A., Cross-Hemmer, A., \& Coalition of Communities of Color (2010). Communities of color in Multnomah County: An unsettling profile. Portland, OR: Portland State University.

Delgado, R., \& Stefancic, J. (1997). Critical white studies: Looking behind the mirror. Philadelphia, PA: Temple.

Dominelli, L. (2002). Anti-oppressive social work theory and practice. New York: Palgrave McMillan.

Fraser, N. (2003). Social justice in the age of identity politics: Redis- 
tribution, recognition and participation. In N. Fraser, \& A. Honneth (Eds.), Redistribution or recognition? A political-philosophical exchange (pp. 7-109). New York: Verso.

Frost, F., \& Shy, K. (1980). Racial differences between linked birth and infant death records in Washington State. American Journal of Public Health, 70, 974-976. doi:10.2105/AJPH.70.9.974

Gracia, J., (Ed.) (2007). Race or ethnicity? On Black and Latino identity. Ithaca, NY: Cornell University Press.

Gracia, J., \& Greiff, P. (Eds.) (2000). Hispanics/Latinos in the United States: Ethnicity, race and rights. New York: Routledge

Har, J. (2010). Minority program helps whites. Oregonian, 6 January, p. B1.

Humes, K., \& Hogan, H. (2009). Measurement of race and ethnicity in a changing, multicultural America. Race and Social Problems, 1, 111-131. doi:10.1007/s12552-009-9011-5

Kiviat, B. (2010). Should the Census be asking people if they are negro? New York: Time Magazine.

http://www.time.com/time/nation/article/0,8599,1955923,00.html

Lawrence-Lightfoot, S. (1994). I've known rivers: Lives of loss and liberation. New York: Addison-Wesley.

McFadden K., \& McShane L. (2010). Use of word Negro on 2010 census forms raises memories of Jim Crow. New York: New York Daily News.

http://www.nydailynews.com/news/2010/01/06/2010-01-06_census_ negro_issue_use_of_word_on_forms_raises_hackles_memories_of_ jim_crow.html

Mullaly, B. (2002). Challenging oppression: A critical social work approach. Don Mills, ON: Oxford.

National Economic Consulting (2001). Effect of census 2000 undercount on federal funding to states and selected counties, 2002-2012. Washington, DC: Price Waterhouse Coopers.

Navarro, M. (2003). Going beyond black and white, Hispanics in Census pick "other." In P. Rothenberg (Ed.), Race, class and gender in the United States (pp. 214-218). New York: Worth.

Oregon Department of Education (2010). 2008 Oregon kindergarten readiness survey report: Readiness to learn. Salem, OR: Oregon Department of Education.

Reamer, A., \& Carpenter, R. (2010). Counting for dollars: The role of the decennial census in the distribution of federal funds. Washington DC: Brookings Institution.

Stehr-Green, P., Bettles, J., \& Robertson, L. (2002). Effect of racial/ethnic misclassification of American Indians and Alaskan Natives on Washington State death certificates, 1989-1997. American
Journal of Public Health, 92, 443-444. doi:10.2105/AJPH.92.3.443

Substance Abuse and Mental Health Services Administration (2009). Results from the 2008 national survey on drug use and health: National findings (Office of Applied Studies, NSDUH Series H-36, HHS Publication No. SMA 09-4434). Rockville, MD.

Sue, D. (2010). Microaggressions in everyday life: Race, gender and sexual orientation. Hoboken, NJ: Wiley.

Tafoya, S. (2004). Shades of belonging. Washington, DC: Pew Hispanic Center.

Urban League of Portland (2009). The state of Black Oregon. Portland, OR: Urban League of Portland.

United Way of the Columbia-Willamette (2007). Community needs assessment 2007. Portland, OR: United Way of the Columbia-Willamette.

US Census Bureau (2004a). Accuracy and coverage evaluation of Census 2000: Design and methodology. Washington, DC: US Department of Commerce.

US Census Bureau (2004b). Meeting 21st century demographic data needs: Implementing the American Community Survey. Suitland, MD: US Department of Commerce. http://www.census.gov/acs/www/AdvMeth/acs_census/creports/Rep ort08.pdf

US Department of Education (2007). Final guidance on maintaining, collecting and reporting racial and ethnic data to the US Department of Education. Washington, DC: US Department of Education. http://www.ed.gov/legislation/FedRegister/other/2007-4/101907c.ht $\mathrm{ml}$

Wilson, E. (2005). Reinventing liberatory practice: How do we work with groups of which we are not a part? International Conference on Engaging Communities-Conference Papers, Queensland, Australia. http://www.engagingcommunities2005.org/abstracts/Wilson-Erin-fin al.pdf

Wilson, G. (2001). Conceptual frameworks and emancipator research in social gerontology. Ageing and Society, 21, 471-487. doi:10.1017/S0144686X01008315

Young, I. (2000). Structure, difference and Hispanic/Latino claims of justice. In J. Gracia, \& P. Greiff (Eds.) Hispanics/Latinos in the United States: Ethnicity, race and rights (pp. 147-165). New York: Routledge.

Young, I., 1990. Justice and the politics of difference. Princeton, New Jersey: Princeton University Press.

Zuberi, T., \& Bonilla-Silva, E., (Eds.) (2008). White logic, white methods: Racism and methodology. Lanham, MD: Rowman \& Littlefield. 